\title{
Morphometric and Histomorphometric Evaluations of High-Purity Macro/Microporous $\beta$-TCP in Maxillary Sinus Floor Elevation
}

Atsushi Fujita ( $\sim$ fujita-a@dokkyomed.ac.jp)

Department of Oral and Maxillofacial Surgery, Dokkyo Medical School of Medicine

Chonji Fukumoto

Dokkyo Medical University: Dokkyo Ika Daigaku

Tomonori Hasegawa

Dokkyo Medical University: Dokkyo Ika Daigaku

Yuta Sawatani

Dokkyo Medical University: Dokkyo Ika Daigaku

Hitoshi Kawamata

Dokkyo Medical University: Dokkyo Ika Daigaku

Research article

Keywords: augmentation, High-purity macro/microporous $\beta$-TCP, maxillary sinus floor elevation

Posted Date: April 8th, 2021

DOI: https://doi.org/10.21203/rs.3.rs-398657/v1

License: (c) (1) This work is licensed under a Creative Commons Attribution 4.0 International License.

Read Full License 


\section{Abstract}

Background: The present study examined the effectiveness of high-purity macro/microporous betatricalcium phosphate (HPMM $\beta$-TCP) as a bone grafting material for maxillary sinus floor elevation by morphometric and histopathological, histomorphometric evaluations.

Methods: Ten maxillary sinus floor elevation procedures using 100\% HPMM $\beta$-TCP were performed on 10 patients. Morphometric evaluation was carried out by CT imaging immediately after augmentation and prior to dental implant placement after 7 months.

Histopathological and histomorphometric evaluation were carried out by bone biopsy retrieval at the time of dental implant placement 7 months after sinus floor elevation.

Results: All 10 sinus floor elevations were successful. Morphometric evaluation by CT images showed that the vertical height and the volume gained by sinus floor elevation decreased 7 months after surgery. Histopathological evaluation by bone biopsy retrieval specimens showed no signs of inflammation at the newly formed bone area and the native alveolar bone area. New bone formation was observed at the cranial side from the native alveolar bone. The newly formed bone had a trabecular structure and was in intimate contact with the HPMM $\beta$-TCP material. Histomorphometric evaluation by bone biopsy retrieval specimens revealed an average new bone volume of $33.97 \% \pm 2.79 \%$ and an average residual HPMM $\beta$ TCP volume of $15.81 \% \pm 4.52 \%$.

Conclusions: In this study, HPMM $\beta$-TCP showed the osteoconductive properties for vertical augmentation of the atrophied maxilla by means of a maxillary sinus floor elevation procedure allowing subsequent dental implant placement after a 7-month healing period.

\section{Background}

Dental implant placement in the posterior maxilla often requires surgical intervention of the maxillary sinus floor area because of insufficient bone volume. Maxillary sinus floor elevation performed for placing the dental implants in this region was first reported by Boyne and James ${ }^{1}$ and Tatum ${ }^{2}$. This surgical procedure makes the dental implant placement possible by increasing the alveolar bone height in this region. A wide variety of graft materials have been used to elevate the maxillary sinus floor. Autogenous bone grafts are considered to be the gold standard, because they are not immunogenic and they have osteogenic, osteoinductive, and osteoconductive properties ${ }^{1,3-6}$. However, there are several disadvantages, including postoperative complications in the donor site such as limping when the graft is taken from the iliac crest, prolonged healing time at the donor site, requirement of general anesthesia and hospitalization, increased cost of treatment, and unpredictable resorption of the new bone by grafting 7,8 . These disadvantages have led to a search for eligible graft materials that are a biocompatible and osteoinductive or at least osteoconductive alternative to autogenous bone substitutes in the sinus floor elevation. 
Various bone-grafting materials such as xenografts (bovine or coralline hydroxyapatite) ${ }^{9-14}$, allografts (freeze-dried demineralized bone) ${ }^{15}$, and alloplasts (hydroxyapatite, beta-tricalcium phosphate, bioactive glass) ${ }^{16-21}$ are presently being used as alternatives or supplements to autogenous bone. These biomaterials act as a scaffold for bone formation ${ }^{22}$.

Anorganic bovine-derived hydroxyapatite (BHA), one of non-resorbable xenograft, has been shown to be a safe and biocompatible bone graft material with osteoconductive properties ${ }^{23-25}$. Also, several experimental and clinical studies have shown successful results of BHA graft materials when used for maxillary sinus floor elevation ${ }^{9-14,22}$. BHA, prepared from Australian cattle, is processed chemically and through heat treatments to remove proteins and other organic substances to ensure the product has no prion and is, thus, non-antigenic ${ }^{26}$. The resulting particles are similar to human bone particles with regard to physical and chemical composition, ensuring the graft provides a conductive scaffold for bone formation. On the other hand, Scolozzi et al. showed a significant association between specific deproteinized bovine bone used as sinus bone graft material and the development of fungus balls of the maxillary sinus, which was based on the presence of chronic maxillary sinusitis with purulent discharge. It was hypothesized that similar to the mechanism of a foreign body reaction, the residual proteins could stimulate an immune response to the xenograft, and that this immune response could promote the Aspergillus growth within the maxillary sinus leading to fungus ball formation ${ }^{27}$. Thus, to prevent the complication of the postoperative maxillary sinusitis caused by fungus ball formation, a bone-grafting material that is protein-free, has good osteoconductive properties and has less residual substitute after bone formation is required for maxillary sinus floor elevation.

Beta-tricalcium phosphate ( $\beta$-TCP), a ceramic alloplast, is a common graft material with osteoconductive properties that has shown promising results ${ }^{28-30}$. Several authors have reported $\beta$-TCP as a satisfactory graft material for the maxillary sinus floor elevation ${ }^{16-22}$. The biomaterial is replaced by newly formed bone ${ }^{31,32}$. Recently high-purity macro/microporous $\beta$-TCP (HPMM $\beta$-TCP: Arrowbone- $\beta$-dental ${ }^{\circledR}$, brainbase $\odot$, Tokyo, Japan) is produced as a resorbable bone substitute.

The purpose of this study was to evaluate the quality and quantity of bone formation in a maxillary sinus floor elevation procedure using only HPMM $\beta$-TCP with a 7-month healing period. The clinical, radiological, morphometric, and histomorphometric results of a multicenter study are presented.

\section{Methods}

\section{Patients}

The study consisted of 10 patients ( 3 male, 7 female) who were partially edentulous in the posterior maxilla and required dental implant placement. The mean age of the patients was $57.2 \pm 2.43$ years (range, 41-67 years). The main criteria for inclusion in the study group were a residual alveolar ridge height of $<5 \mathrm{~mm}$ and a width of $\geq 5 \mathrm{~mm}$. Panoramic radiographs were taken, and these radiographs were used to evaluate the residual alveolar ridge height. The surgical phase was planned as a maxillary sinus 
floor elevation followed by dental implant placement. The exclusion criteria were unsatisfactory oral hygiene, cute maxillary sinusitis, heavy smoking ( $\geq 10$ cigarettes a day), and systemic diseases such as uncontrolled diabetes mellitus. All patients were healthy, with no disease that might affect the treatment outcome. The patients were fully informed about the procedures, including the surgery, graft materials, and dental implants, and written, informed consent was obtained from all of them. The research protocol was approved by the Ethics Committee of Dokkyo Medical University School of Medicine (R-10-14).

HPMM $\beta-T C P$

HPMM $\beta$-TCP is a monophase $\beta$-TCP ceramic generated by the spray-dry method. The synthesized granules are recognized as high purity by $\mathrm{X}$-ray diffraction analysis (Fig. 1). Osteogenic cellular activity requires bone substitutes with porous spaces that allow cellular penetration in order to obtain the most suitable porosity, optimal pore size, and favorable pore structure. HPMM $\beta$-TCP is a granular bone substitute with a diameter of 250 to $2000 \mu \mathrm{m}$ formed as a bunch of grapes. Primary particles, having many micropores with a diameter of $3 \mu \mathrm{m}$, are microspheric with a diameter of $50 \mu \mathrm{m}$, and there are many interconnecting pores $(10-160 \mu \mathrm{m})$ between secondary particles of HPMM $\beta$-TCP ceramics (Fig. 2). It is hydrophilic and has a porosity of $75 \%$.

Maxillary sinus floor elevation procedure, dental implant placement, and bone biopsy retrieval

For maxillary sinus floor elevation, 9 patients were treated with an outpatient procedure under local anesthesia, while 1 patient was treated under local anesthesia with intravenous sedation. The antibiotic (amoxicillin $1000 \mathrm{mg}$ four times a day) for 7 days, and an oral rinse with chlorhexidine digluconate $0.006 \%$ ( $10 \mathrm{~cm}^{3}$ three times daily for $\left.1 \mathrm{~min}\right)$ for 2 weeks were prescribed for all patients. Via crestal incision and elevation of a mucoperiosteal flap, the maxillary wall was prepared. Preparation was made in the lateral maxillary sinus wall using a round burr with irrigation with sterile saline. A buccal window together with the carefully elevated sinus membrane was dissected and reflected inward. The sinus membrane was detached from the maxillary walls and moved in cranial direction. In all cases, the sinus membrane was covered with a resorbable collagen membrane (Bio-Gide ${ }^{\circledR}$, Geistlich Pharma AG, Wolhusen, Switzerland). The space between the lifted sinus membrane and the sinus floor was filled with HPMM $\beta$-TCP (Fig. 3). Complete wound closure was performed with 4/0 monofilament sutures. Removal of sutures was performed after two weeks. After a 7-month healing period, elevation of a mucoperiosteal flap was performed for dental implant placement under local anesthesia in all cases. Before dental implant preparations were made, bone biopsies were taken using a trephine drill with an external diameter of $3.3 \mathrm{~mm}$ from the grafted area at the planned dental implant positions, with irrigation with sterile saline. The dental implant bodies with a length of 10 or $12 \mathrm{~mm}$ and diameter of $4.0 \mathrm{~mm}$ could be placed into the implant bed in all patients. Sutures were removed 10 days after dental implant placement. All surgical procedures were performed by one oral surgeon (AF). Attention was paid to prevent premature loading of the dental implants. Attention was paid to prevent premature loading of the dental implant. After a healing period of 6 months, the implants were loaded. 
Panoramic radiographs and CT images were taken before surgery, after the maxillary sinus floor elevation procedure, and prior to dental implant placement. CT images were stored in DICOM format data, which were analyzed in SIMPLANT ${ }^{\circledR}$ Pro 16 (Dentspy Sirona Inc., New York, USA), a reformatting imaging software package that simulates the placement of dental implants. Images were analyzed by an independent experienced dentist without any clinical information (HK). No information about group assignment was provided during the examinations (Fig. 4).

Histopathological and histomorphometric evaluation by bone biopsy

The specimens were placed in $4 \%$ formalin solution for 72 hours and then in the $6 \%$ nitric acid solution for 12 hours. The specimens were washed for 4 hours. They were dehydrated in an ascending series in alcohol and xylene. Bone cores were finally embedded in paraffin. Fine cut, $5-\mu \mathrm{m}$-thick sections were made from each specimen parallel to the long axis of the cylindrical core using a microtome. Subsequent to deparaffinization of the sections, they were exposed to a descending series of alcohol and xylene, then washed with water. Finally, the specimens were stained with hematoxylin and eosin (H\&E).

Images of the sections were obtained with a digital camera (Olympus DP 80, Olympus, Tokyo, Japan) attached to a microscope (Olympus BX53, Olympus). The obtained images were transferred to a computer, and image analysis software (WinROOF2015 Standard®, Mitani Co., Fukui, Japan) was used for histomorphometric evaluations. Histomorphometric evaluations were performed over the total section of the biopsy, including residual and newly formed bone. Newly formed bone of the biopsy was defined as the area from the first visible HPMM $\beta$-TCP particle at the cranial side of the native alveolar bone (Fig. 5). The following histomorphometric measurements were performed: (1) new bone formation in the grafted area (percentage of newly formed bone area to total measured area); (2) area of graft particles (percentage of graft particle area to total measured area); and (3) soft-tissue area in the grafted zone (percentage of soft-tissue area to total measured area).

\section{Statistical analysis}

The results of the morphometric analyses were calculated as the means \pm SEM for each variable. The significance of differences between groups was tested by Student's $t$-test. $P$ values $<0.05$ were considered significant.

\section{Results}

Clinical evaluation

All 10 sinus floor elevations were successful. And all dental implant placements were also successful. The surgical site infection was not observed. The mean healing time after the maxillary sinus floor elevation was $226.7 \pm 12.3$ days (range, $175-288$ days; Fig. 6 ). 
CT images were evaluated to assess the height of the most increased position in the maxillary grafted materials after sinus floor elevation, as well as the height of the same position prior to dental implant placement. The average height after the maxillary sinus floor elevation was $15.60 \pm 0.88 \mathrm{~mm}$. The average height prior to dental implant placement was $11.27 \pm 1.09 \mathrm{~mm}$. The rate of change in the average height from the maxillary sinus floor elevation to dental implant placement was $72.61 \% \pm 6.44 \%$. The average height was significantly lower prior to dental implant placement than after sinus floor elevation (Fig. 7).

CT images were evaluated to assess the increased volume of the maxillary bone after sinus floor elevation, as well as prior to dental implant placement. The average volume of the grafted maxillary bone after sinus floor elevation was $2674.39 \pm 453.34 \mathrm{~mm}^{3}$. The average volume of the grafted maxillary bone prior to dental implant placement was $1516.88 \pm 246.71 \mathrm{~mm}^{3}$. The rate of change in the average volume from the maxillary sinus floor elevation to dental implant placement was $61.45 \% \pm 6.01 \%$. The average volume was significantly lower prior to dental implant placement than after sinus floor elevation (Fig. 8).

Histopathological evaluation

Histopathological examinations showed no infiltration of inflammatory cells in the tissue close to the grafted material. New bone formation was examined in all 10 specimens. The trabecular bone that formed from the residual bone expanded the grafted space. The new bone consisted of both lamellar and woven bone. Osteocytes were present in the lacunae. In 9 of 10 specimens, the primary trabecular structure was already reinforced by lamellar bone in some areas. The HPMM $\beta$-TCP particles were integrated into the circuitry of newly formed trabecular bone. Close bone-to-substitute contact was observed. Osteoblasts were detected next to the characteristic outlines of the newly formed bone (Figs. 9, 10).

Histomorphometric evaluation

Table 1 shows the results of the histomorphometric measurements of HPMM $\beta$-TCP. Mean new bone formation was $33.97 \% \pm 2.79 \%$. The mean percentage of residual grafted particle area was $15.81 \% \pm 4.52 \%$. The mean percentage of soft-tissue area was $50.21 \% \pm 4.28 \%$ (Table 1 ).

\section{Discussion}

In this study, the maxillary sinus floor elevation procedures using HPMM $\beta$-TCP showed uneventful healing. Morphometric evaluation by CT images showed that the vertical height and the volume gained by sinus floor elevation decreased 7 months after surgery. The average height after the maxillary sinus floor elevation was $15.60 \pm 0.88 \mathrm{~mm}$. The average height prior to implant insertion was $11.27 \pm 1.09 \mathrm{~mm}$. The rate of change in the average height from the maxillary sinus floor elevation to implant insertion was $72.61 \% \pm 6.44 \%$. Histological investigation also showed no signs of inflammation at the newly formed 
bone area and the native alveolar bone area. Cranial from the native alveolar bone, newly formed mineralized tissue was observed. The newly formed bone had a trabecular structure and was in close contact with the HPMM $\beta$-TCP particles. Histomorphometric evaluation revealed an average new bone volume of $33.97 \% \pm 2.79 \%$ and an average residual HMM $\beta$-TCP volume of $15.81 \% \pm 4.52 \%$. The results indicated that HPMM $\beta$-TCP, a new bone substitute, was thought to have good osteoconductive properties with proper absorbency characteristics. The amount of HPMM $\beta$-TCP filled in the maxillary sinus bed for elevation should be planed as overcorrection that compensates for the expected resorption.

TCP is biocompatible, osteoconductive calcium phosphate. The biomaterial can provide a scaffold for potential bony ingrowth ${ }^{33}$. TCP resorbs, unlike BHA. It is replaced by newly formed bone ${ }^{31,32}$. The problem is that this replacement does not necessarily occur in a 1:1 ratio. Often less bone is produced as compared with the volume of TCP resorbed $20,21,34$. Several authors have reported $\beta$-TCP as a satisfactory graft material for augmentation of the maxillary sinus ${ }^{16-22,28-32}$. Wiltfang et al. reported the degradation characteristics of $\beta$-TCP in minipigs. In seven Goettingen minipigs, $3.5-4.7 \mathrm{ml}$ of cancellous bone defects was created in the area of the tibial head. And the defects were filled with $\beta$-TCP. After 86 weeks, approximately $3 \% \beta$-TCP was still found. These residual particles stay within the newly formed trabeculae, which show a functional orientation. Following absorption and bony substitution, $\beta$-TCP ceramics allowed a restitutio ad integrum at the grafted bone tissue ${ }^{35}$.

Zijderveld et al. reported maxillary sinus floor augmentation with $\beta$-TCP (Cerasorb; Curasan, Kleinostheim, Germany) using the same method as the present study ${ }^{21}$. According to their results, mean new bone formation was $17 \% \pm 5 \%$, and the mean percentage of residual graft particle area 6 months postoperatively was $31 \% \pm 4 \%{ }^{21}$. The present study showed that HPMM $\beta$-TCP has a good balance with bone formation and material absorption. We consider that the reason for these results was both the high purity and the macro/microporous structure of HPMM $\beta$-TCP. The greater volume of new bone formation using $100 \%$ HPMM $\beta$-TCP was confirmed with the lower percentages of residual graft particles in comparison with $\beta$-TCPs ${ }^{21,36-38}$ (Table 2).

Histologically, the vital bone was composed of both lamellar and woven bone. Osteocytes were present in the lacunae. The newly formed bone was in intimate contact with the substitute material, outlining the osteoconductive properties of the HPMM $\beta$-TCP material. Bone maturation was evident by the presence of lamellar bone. Osteoblasts were detected next to the characteristic outlines of the newly formed bone (Figs. 9, 10). Retrograde infection with viruses and bacteria via the ostomeatal complex from the nasal cavity causes acute paranasal sinusitis. If there is no activity in the bone of the maxillary sinus, paranasal sinusitis will get worse. And the inactive bone of the maxilla has no potential as supporting tissue for dental implants. Therefore, bone activity is important for the alveolar part of the posterior maxilla for dental implants.

BHA is a deproteinized natural bovine cancellous bone with a crystalline structure that is very similar to human bone. The deproteinization process through chemical and heat treatments should eliminate any immunogenicity concerns. However, Schwartz et al. suggested that BHA can contain osteoinductive 
proteins, such as transforming growth factor- $\beta$, bone morphogenic protein, and bone morphogenic protein-2, which can elicit an immune response ${ }^{39}$. One case report presented a foreign body reaction in a patient who had undergone alveolar ridge augmentation with a mixture of $\mathrm{BHA}$ and autogenous bone ${ }^{40}$. The most plausible explanation for such a reaction is an interaction between residual proteins within BHA particles with adhesion receptors present on monocyte/macrophage inflammatory cell populations. Scolozzi et al. hypothesized that similar to the mechanism of a foreign body reaction, the residual proteins could stimulate an immune response to the xenograft and that this immune response could promote Aspergillus growth within the maxillary sinus leading to fungus ball formation ${ }^{27}$. Thus, in order to prevent complications such as a postoperative maxillary sinusitis caused by a fungus ball, a proteinfree bone-grafting material with less residual substitute after bone formation and with good osteoconductive properties, such as HPMM $\beta$-TCP is ideal for maxillary sinus floor elevation.

\section{Conclusions}

In this study, HPMM $\beta$-TCP showed the osteoconductive properties for vertical augmentation of the atrophied maxilla by means of a maxillary sinus floor elevation procedure allowing subsequent dental implant placement after a 7-month healing period. Histological and histomorphometric evaluation showed newly formed bone with a trabecular structure. Osteocytes were present in the lacunae. The newly formed bone was in close contact with the HPMM $\beta$-TCP material, outlining the osteoconductive properties of the HPMM $\beta$-TCP material. The presence of lamellar bone was evidence of bone maturation. Osteoclasts were detected next to the characteristic outlines of the newly formed bone.

Histomorphometric evaluation revealed an average new bone volume of $33.97 \% \pm 2.79 \%$ and an average residual HPMM $\beta$-TCP volume of $15.81 \% \pm 4.52 \%$.

The results indicated that HPMM $\beta$-TCP, a new bone substitute, was thought to have good osteoconductive properties with proper absorbency characteristics.

\section{Abbreviations}

HPMM $\beta$-TCP: High-purity macro/microporous beta-tricalcium phosphate

BHA: Bovine-derived hydroxyapatite

$\beta$-TCP: Beta-tricalcium phosphate

H\&E: Hematoxylin and eosin staining

\section{Declarations}

\section{Availability of supporting data}


The datasets generated and analyzed during the current study are available from the corresponding author upon reasonable request.

\section{Ethical approval and Consent to participate:}

The study protocol was approved by the Ethics Committee of Dokkyo Medical University School of Medicine (R-10-14). The consents of the patients have been obtained.

\section{Consent for publication}

Not applicable.

\section{Competing interests}

Not applicable.

\section{Funding}

Not applicable.

\section{Authors' contributions}

AF: Concept/Design, Data analysis/interpretation, Drafting article, Statistics, Data collection.

CF: Data analysis/interpretation, Critical revision of article, Statistics, Approval of article.

TH: Data analysis/interpretation, Critical revision of article, Statistics, Approval of article.

YS: Data analysis/interpretation, Critical revision of article, Statistics, Approval of article.

HK: Concept/Design, Data analysis/interpretation, Critical revision of article, Statistics, Approval of article

\section{Acknowledgements}

Not applicable

\section{References}

1. Boyne PJ, James RA. Grafting of the maxillary sinus floor with autogenous marrow and bone. J Oral Surg. 1980; 38: 613-6.

2. Tatum H. Maxillary and sinus implant reconstructions. Dent Clin North Am. 1986; 30: 207-22.

3. Jensen SS, Shulman LB, Block MS, lacono VJ. Report of the sinus consensus conference of 1996. Int J Oral Maxillofac Implants. 1998; 13: 11-45.

4. Block MS, Kent JN. Sinus augmentation for dental implants: the use of autogenous bone. J Oral Maxillofac Surg. 1997; 55: 1281-6. 
5. Moy PK, Lundgren S, Holmes RE. Maxillary sinus augmentation: histomorphometric analysis of graft materials for maxillary sinus floor augmentation. J Oral Maxillofac Surg. 1993; 51: 857-62.

6. Pejrone G, Lorenzetti M, Mozzati M, Valente G, Schierona GM. Sinus floor augmentation with autogenous iliac bone block grafts: a histological and histomorphometrical report on the twostep surgical technique. Int J Oral Maxillofac Implants. 2002; 31: 383-8.

7. Younger EM, Chapman MW. Morbidity at bone graft donor sites. J Orthop Trauma. 1989; 3: 192-5.

8. Kalk WWL, Raghoebar GM, Jansma J, Boering G. Morbidity from iliac crest bone harvesting. J Oral Maxillofac Surg. 1996; 54: 1424-9.

9. Hürzeler MB, Quinones CR, Kirsch A, Gloker C, Schüpbach P, Strub JR, Caffesse RG. Maxillary sinus augmentation using different grafting materials and dental implants in monkeys. Part I. Evaluation of anorganic bovine-derived bone matrix. Clin Oral Implants Res. 1997; 8: 476-86.

10. Valentini P, Abensur DJ. Maxillary sinus grafting with anorganic bovine bone: a clinical report of longterm results. Int J Oral Maxillofac Implants. 2003; 18: 556-60.

11. Yıldırım M, Spiekermann H, Biesterfeld S, Edelhoff D. Maxillary sinus augmentation using xenogenic bone substitute material Bio-Oss in combination with venous blood: a histologic and histomorphometric study in humans. Clin Oral Implants Res. 2000; 11: 217-29.

12. Haas R, Donath K, Födinger M, Watzek G. Bovine hydroxyapatite for maxillary sinus grafting: comparative histomorphometric findings in sheep. Clin Oral Implants Res. 1998; 9: 107-16.

13. Sartori S, Silvestri M, Forni F, Icaro Cornaglia A, Tesei P, Cattaneo V. Ten-year follow-up in a maxillary sinus augmentation using anorganic bovine bone (Bio-Oss): a case report with histomorphometric evaluation. Clin Oral Implants Res. 2003; 14: 369-72.

14. Benlidayi ME, Kurkcu M, Oz IA, Sertdemir Y. Comparison of two different forms of bovine-derived hydroxyapatite in sinus augmentation and simultaneous implant placement: an experimental study. Int J Oral Maxillofac Implants. 2019; 24: 704-11.

15. Avila G, Neiva R, Misch CE, Galindo-Moreno P, Benavides E, Rudek I, Wang HL. Clinical and histologic outcomes after the use of a novel allograft for maxillary sinus augmentation: a case series. Implant Dent. 2010; 19: 330-41.

16. Tadjoedin ES, de Lange GL, Lyaruu DM, Kuiper L, Burger EH. High concentrations of bioactive glass material (BioGran) vs. autogenous bone for sinus floor elevation. Clin Oral Implants Res. 2002; 13: 428-36.

17. Quinones CR, Hürzeler MB, Schüpbach P, Kirsch A, Blum P, Caffesse RG, Strub JR. Maxillary sinus augmentation using different grafting materials and osseointegrated dental implants in monkeys. Part II: evaluation of porous hydroxyapatite as a grafting material. Clin Oral Implants Res. 1997; 8: 487-96.

18. Szabo G, Suba Z, Hrabak K, Barabas J, Nemeth Z. Autogenous bone versus beta-tricalcium phosphate graft alone for bilateral sinus elevations (2- and 3-dimensional computed tomographic, histologic, and histomorphometric evaluation): preliminary results. Int J Oral Maxillofac Implants. 2001; 16: 681-92. 
19. Szabo G, Huys L, Coulthard P, Maiorana C, Garagiola U, Barabás J, Németh Z, Hrabák K, Suba Z. A prospective multicenter randomized clinical trial of autogenous bone versus beta-tricalcium phosphate graft alone for bilateral sinus elevation: histologic and histomorphometric evaluation. Int J Oral Maxillofac Implants. 2005; 20: 371-81.

20. Zerbo IR, Zijderveld SA, de Boer A, Bronckers ALJJ, de Lange G, ten Bruggenkate CM, Burger EH. Histomorphometry of human sinus floor augmentation using a porous beta-tricalcium phosphate: a prospective study. Clin Oral Implants Res. 2004; 15: 724-32.

21. Zijderveld SA, Zerbo IR, van den Bergh JPA, Schulten EAJM, ten Bruggenkate CM. Maxillary sinus floor augmentation using a beta-tricalcium phosphate (Cerasorb) alone compared to autogenous bone grafts. Int J Oral Maxillofac. 2005; 20: 432-40.

22. Simunek A, Kopecka D, Somanathan RV, Pilathadka S, Brazda T. Deproteinized bovine bone versus beta-tricalcium phosphate in sinus augmentation surgery: a comparative histologic and histomorphometric study. Int J Oral Maxillofac Implants. 2008; 23: 935-42.

23. Berglundh T, Lindhe J. Healing around implants placed in bone defects treated with Bio-Oss: an experimental study in the dog. Clin Oral Implants Res. 1997; 8: 117-24.

24. Hammerle CH, Olah AJ, Schmid J, Flückiger L, Gogolewski S, Winkler JR, Lang NP. The biological effect of natural bone mineral on bone formation on the rabbit skull. Clin Oral Implants Res 1997: 8: 198-207.

25. Peetz M. Characterization of xenogenic bone material. In: Boyne PJ, Evensen L, eds. Osseous Reconstruction of the Maxilla and the Mandible: Surgical Techniques Using Titanium Mesh and Bone Mineral. Carol Stream, IL: Quintessence; 1997: 87-100.

26. Wenz B, Oesch B, Horst M. Analysis of the risk of transmitting bovine spongiform encephalopathy through bone grafts derived from bovine bone. Biomaterials. 2001; 22: 1599-1606.

27. Scolozzi P, Perez A, Verdeja R, Courvoisier DS, Lombardi T. Association between maxillary sinus fungus ball and sinus bone grafting with deproteinized bovine bone substitutes: a case-control study. Oral Surg Oral Med Oral Pathol Oral Radiol. 2016; 121: e143-7. doi: 10.1016/j.oooo.2016.01.022

28. Breitbart AS, Staffenberg DA, Thorne CH, Glat pM, Cunningham NS, Reddi AH, Ricci J, Steiner G. Tricalcium phosphate and osteogenin: a bioactive onlay bone graft substitute. Plast Reconstr Surg. 1995; 96: 699-708.

29. Buser D, Hoffmann B, Bernard JP, Lussi A, Mettler D, Schenk RK. Evaluation of filling materials in membrane protected bone defects: a comparative histomorphometric study in the mandible of miniature pigs. Clin Oral Implants 1998: 9: 137-50.

30. Ohsawa K, Neo M, Matsuoka H, Akiyama H, Ito H, Kohno H, Nakamura T. The expression of bone matrix protein mRNAs around beta-TCP particles implanted into bone. J Biomed Mater Res. 2000; 52: 460-6.

31. LeGeros, RZ, Lin S, Rohanizadeh, R, Mijares D, LeGeros JP. Biphasic calcium phosphate bioceramics: preparation, properties and applications. J Materi Sci Mater Med. 2003; 14: 201-9. 
32. Schopper C, Ziya-Ghazvini F, Goriwoda W, Moser D, Wanschitz F, Spassova E, Lagogiannis G, Auterith A, Ewers R. HA/TCP compounding of a porous CaP biomaterial improvesbone formation and scaffold degradation - a long-term histological study. J Biomed Mater Res B Appl Biomater. 2005; 74: 458-67.

33. Daculsi G, Laboux O, Malard O, Weiss P. Current state of the art of biphasic calcium phosphate bioceramics. J Mater Sci Mater Med. 2003; 14: 195-200.

34. Jensen SS, Broggini N, Hjorting-Hansen E, Schenk R, Buser D. Bone healing and graft resorption of autograft, anorganic bovine bone and $\beta$-tricalcium phosphate. A histologic and histomorphometric study in the mandibles of minipigs. Clin Oral Implants Res. 2006; 17: 237-43.

35. Wiltfang J, Merten HA, Schlegel KA, Schultze-Mosgau S, Kloss FR, Rupprecht S, Kessler P. Degradation characteristics of alpha and beta tri-calcium-phosphate (TCP) in minipigs. J Biomed Mater Res. 2002; 63:115-21.

36. Cömert Kılıç S, Güngörmüş M, Parlak SN. Histologic and histomorphometric assessment of sinusfloor augmentation with beta-tricalcium phosphate alone or in combination with pure-platelet-rich plasma or platelet-rich fibrin: A randomized clinical trial. Clin Oral Implants Res. 2017; 19: 959-67.

37. Jelusic D, Zirk ML, Fienitz T, Plancak D, Puhar I, Rothamel D. Monophasic ß-TCP vs. biphasic HA/ßTCP in two-stage sinus floor augmentation procedures - a prospective randomized clinical trial. Clin Oral Implants Res 2017: 28: e175-83. doi: 10.1111/clr.12983

38. Kurkcu M, Benlidayi ME, Cam B, Sertdemir Y. Anorganic bovine-derived hydroxyapatite vs $\beta$-tricalcium phosphate in sinus augmentation: a comparative histomorphometric study. J Oral Implantol. 2012; 38: Spec 519-26.

39. Schwartz Z, Weesner T, van Dijk S, Cochran DI, Mellonig JT, Lohmann CH, Carnes DL, Goldstein M, Dean DD, Boyan BD. Ability of deproteinized cancellous bovine bone to induce new bone formation. J Periodontol. 2000; 71: 1258-69.

40. Bannister SR, Powell CA. Foreign body reaction to anorganic bovine bone and autogenous bone with platelet-rich plasma in guided bone regeneration. J Periodontol. 2008; 79: 1116-20.

\section{Tables}

Table 1. Mean percentages of new bone, graft particles, and soft tissue areas 


\begin{tabular}{ccc} 
Parameter & Mean & SEM \\
\hline New Bone, \% & 33.97 & 2.79
\end{tabular}

Graft Particles, \% $\quad 15.81 \quad 4.52$

Soft Tissue areas, $\% \quad 50.21 \quad 4.28$

Table 2. Comparison of the $\beta$-TCPs and HPMM $\beta$-TCP

\begin{tabular}{lll} 
Bone substitute & New Bone, \% & Graft Particles, \% \\
\hline$\beta$-TCP A & $17.5 \pm 5$ & $31 \pm 4$
\end{tabular}

(Cerasorb ${ }^{\circledR 21}$ )

$\beta$-TCP B $\quad 33.40 \pm 10.43 \quad 30.39 \pm 10.29$

(Suprabone ${ }^{36}$ )

$\begin{array}{lll}\beta \text {-TCP C } & 36.16 \pm 12.61 & 30.26 \pm 11.70\end{array}$

(Bioresorb ${ }^{\circledR 3}$ )

$\begin{array}{lll}\beta \text {-TCP D } & 21.09 \pm 2.86 & 34.05 \pm 3.01\end{array}$

$\left(\right.$ Kasios $^{\circledR} \mathrm{TCP}{ }^{38}$ )

HPMM $\quad \beta$-TCP $\quad 33.97 \pm 7.98(\mathrm{SDs}) \quad 15.81 \pm 14.78$ (SDs)

(Arrowbone- $\beta$ - dental ${ }^{\circledR}$ )

Figures 

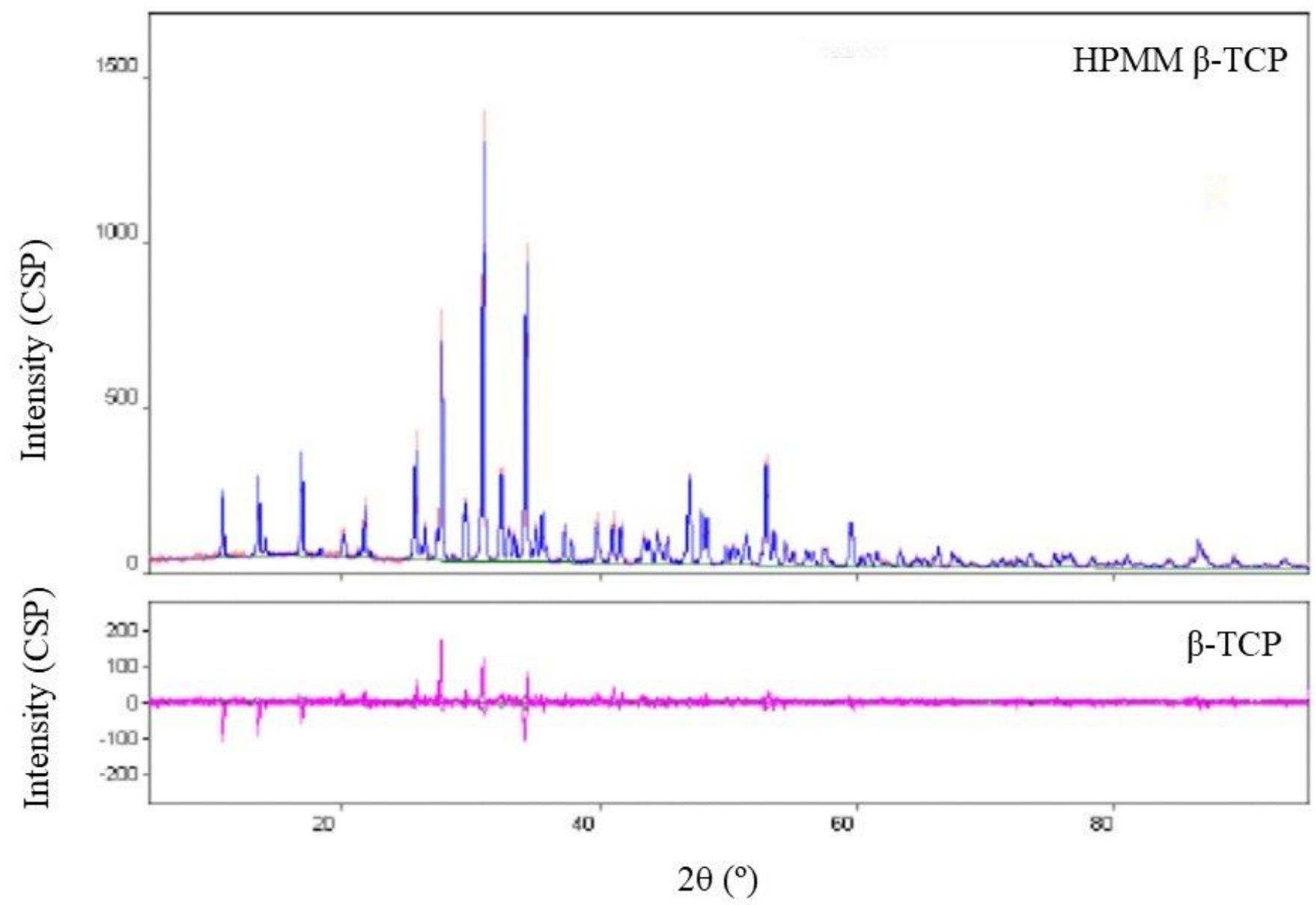

Figure 1

Analysis of X-ray diffraction of HPMM $\beta$-TCP 


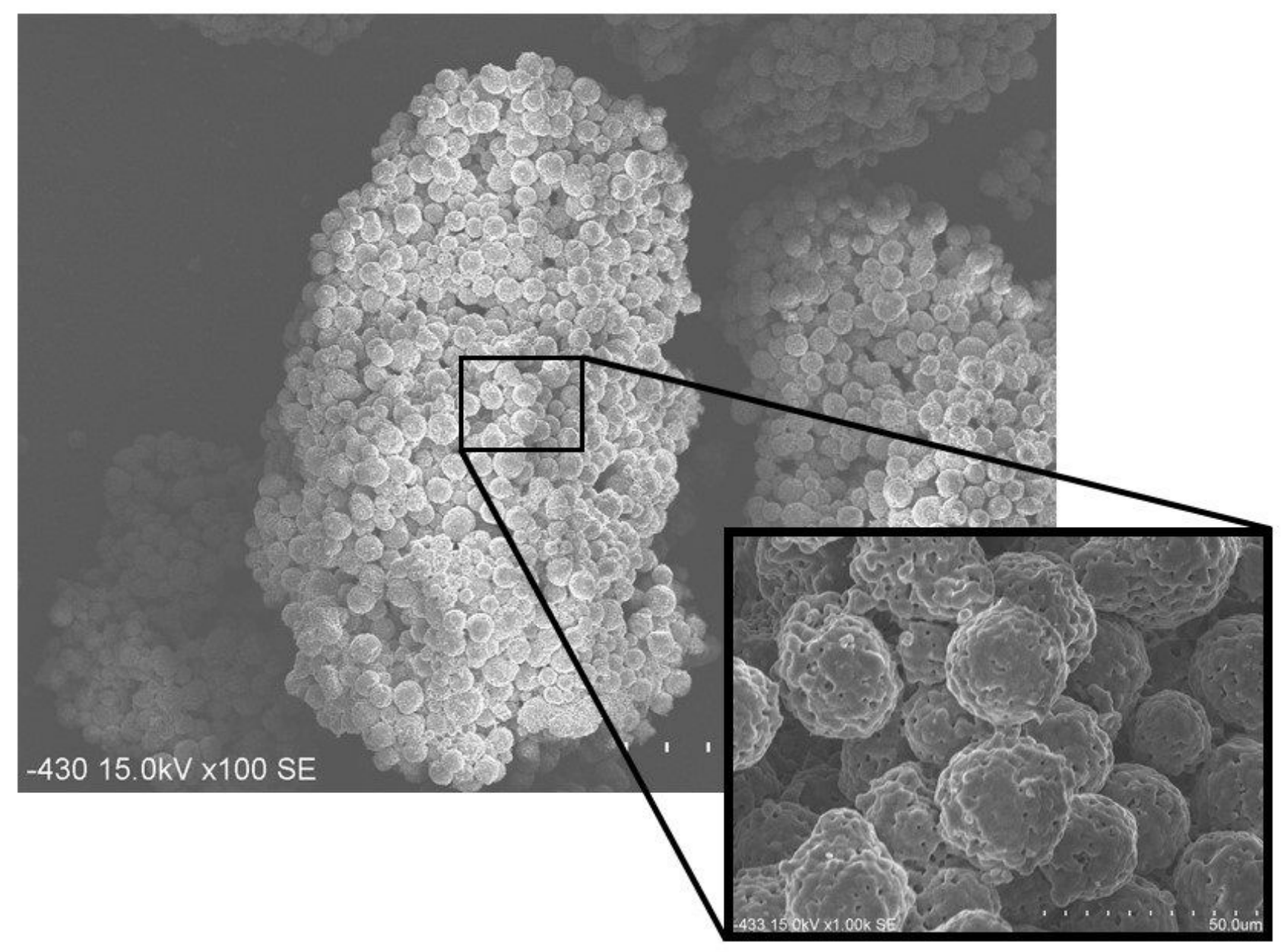

Figure 2

SEM micrograph of HPMM $\beta$-TCP 


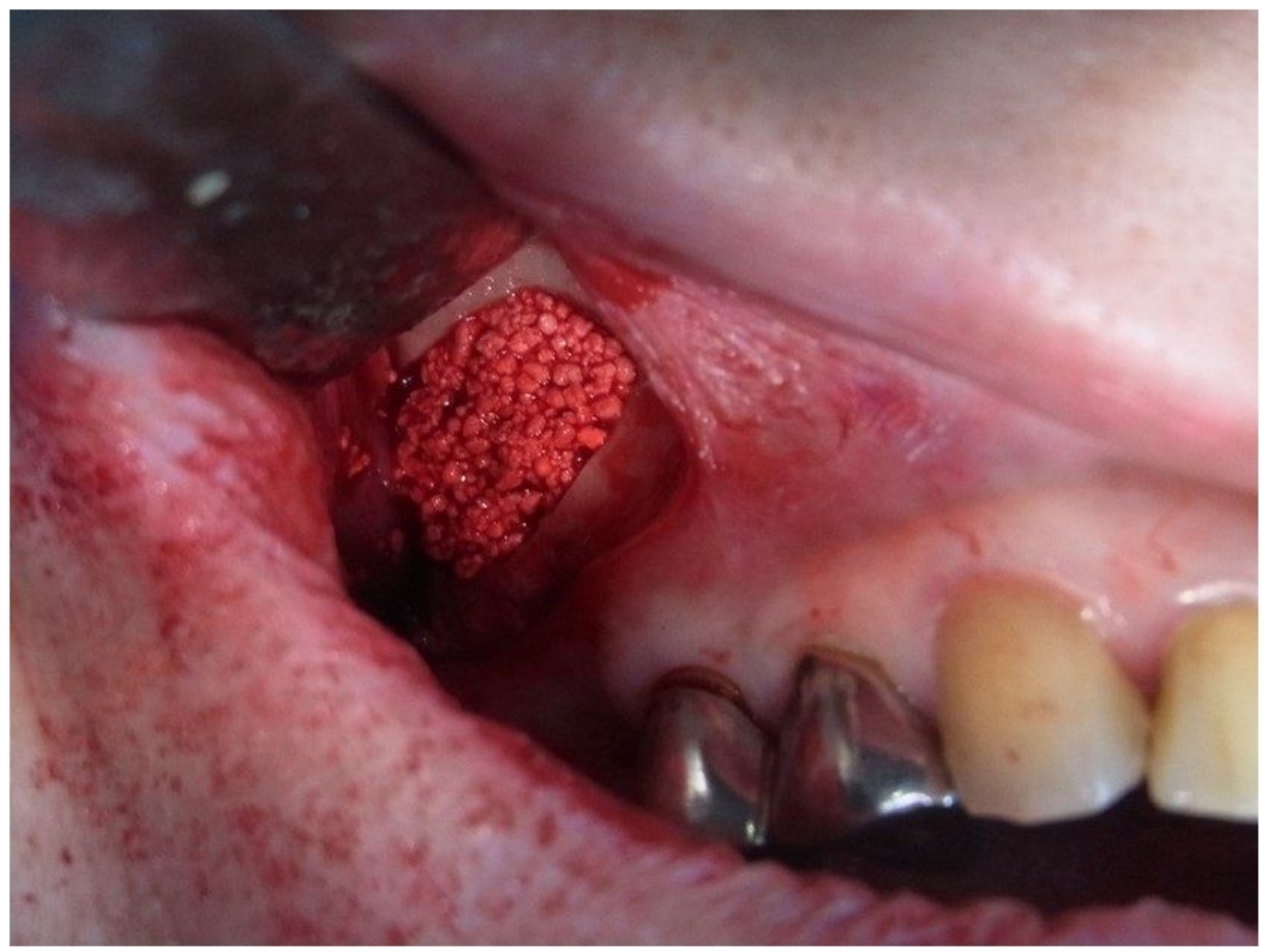

Figure 3

Use of HPMM $\beta$-TCP with a resorbable collagen membrane in sinus floor elevation. 


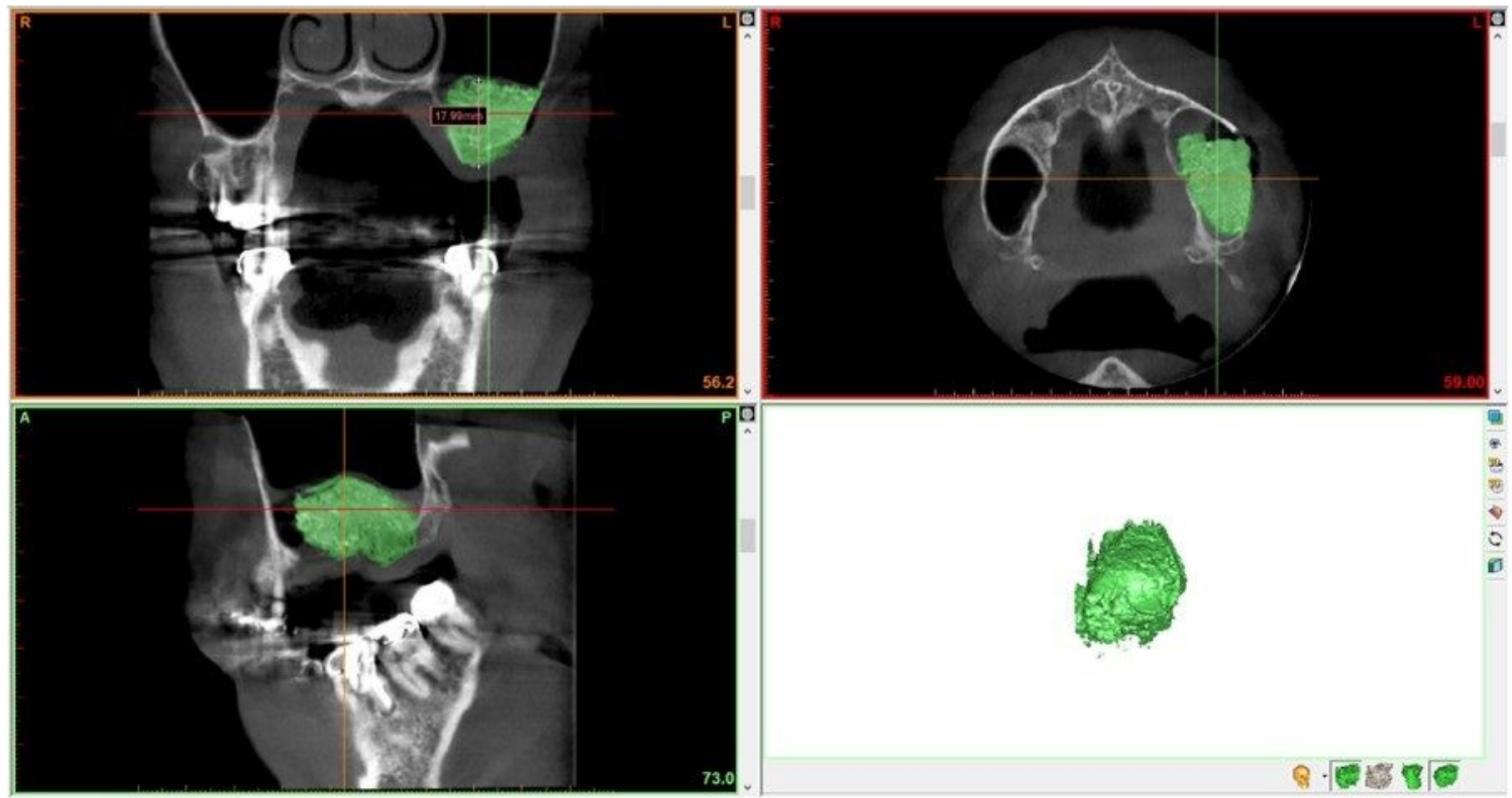

Figure 4

Analysis of the height and volume of the augmented bone using the reformatting imaging software. 

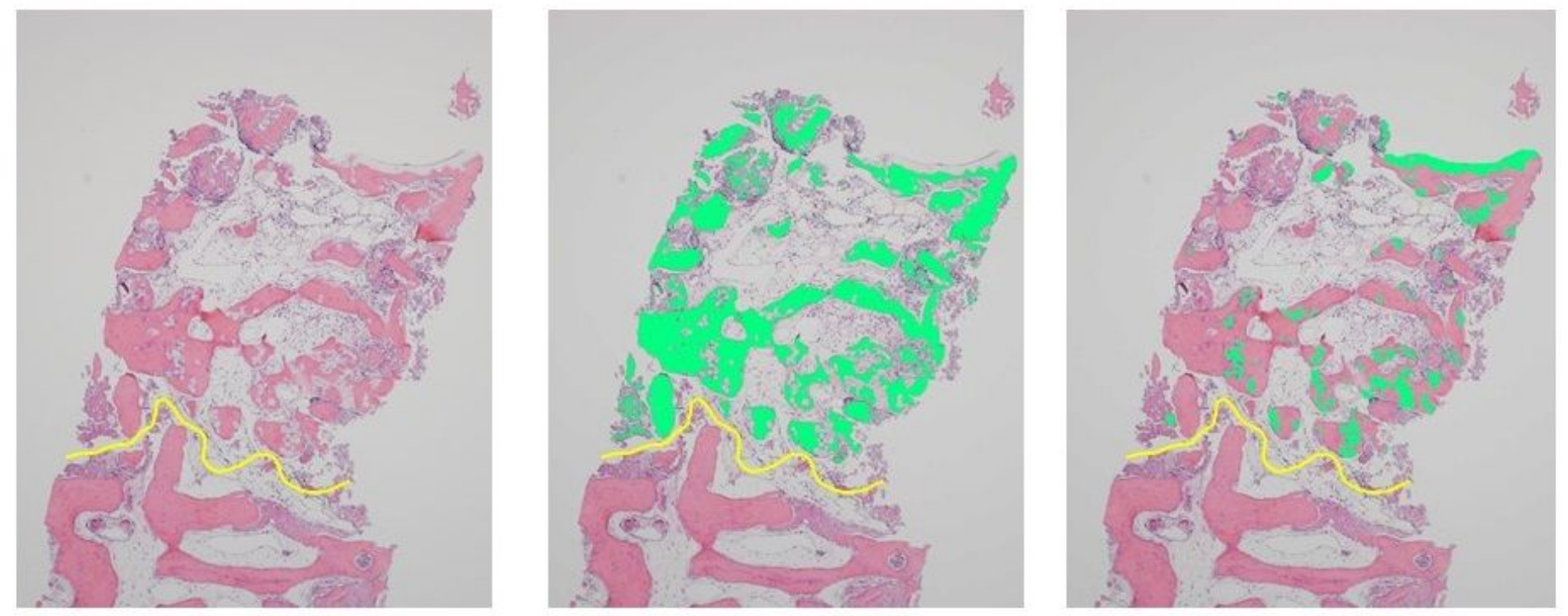

A

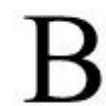

$\mathrm{C}$

\section{Figure 5}

Overview of a typical example of a bone biopsy. A: Newly formed bone area and native alveolar bone area divided by the yellow line. B: Newly formed bone area filled by yellowish green. C: Residual graft particles area filled by yellowish green. 


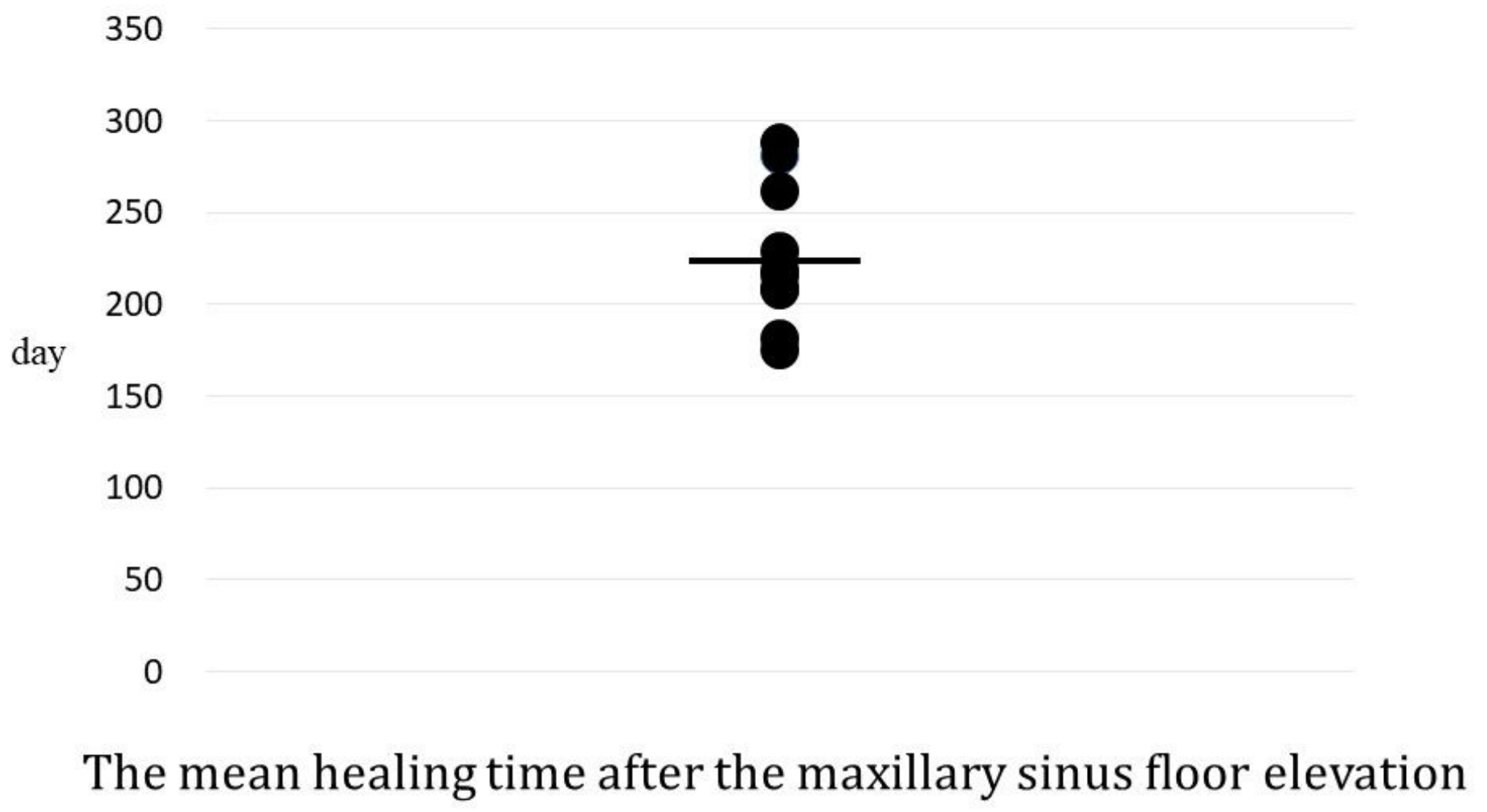

Figure 6

The mean healing time after maxillary sinus floor elevation. 


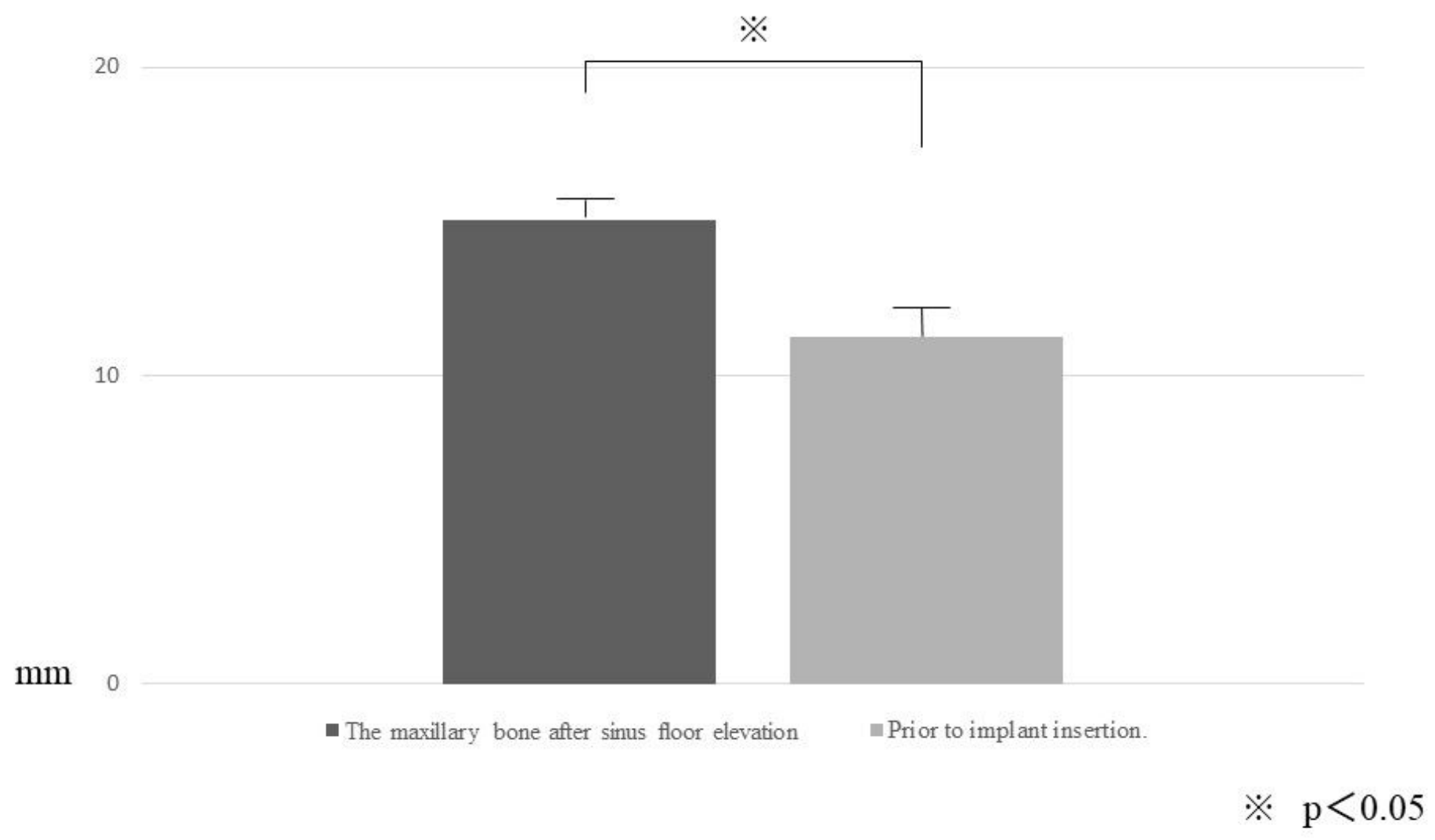

Figure 7

The average heights of the maxillary bone after sinus floor elevation and prior to implant insertion. The average height prior to implant insertion is significantly lower than after sinus floor elevation. 


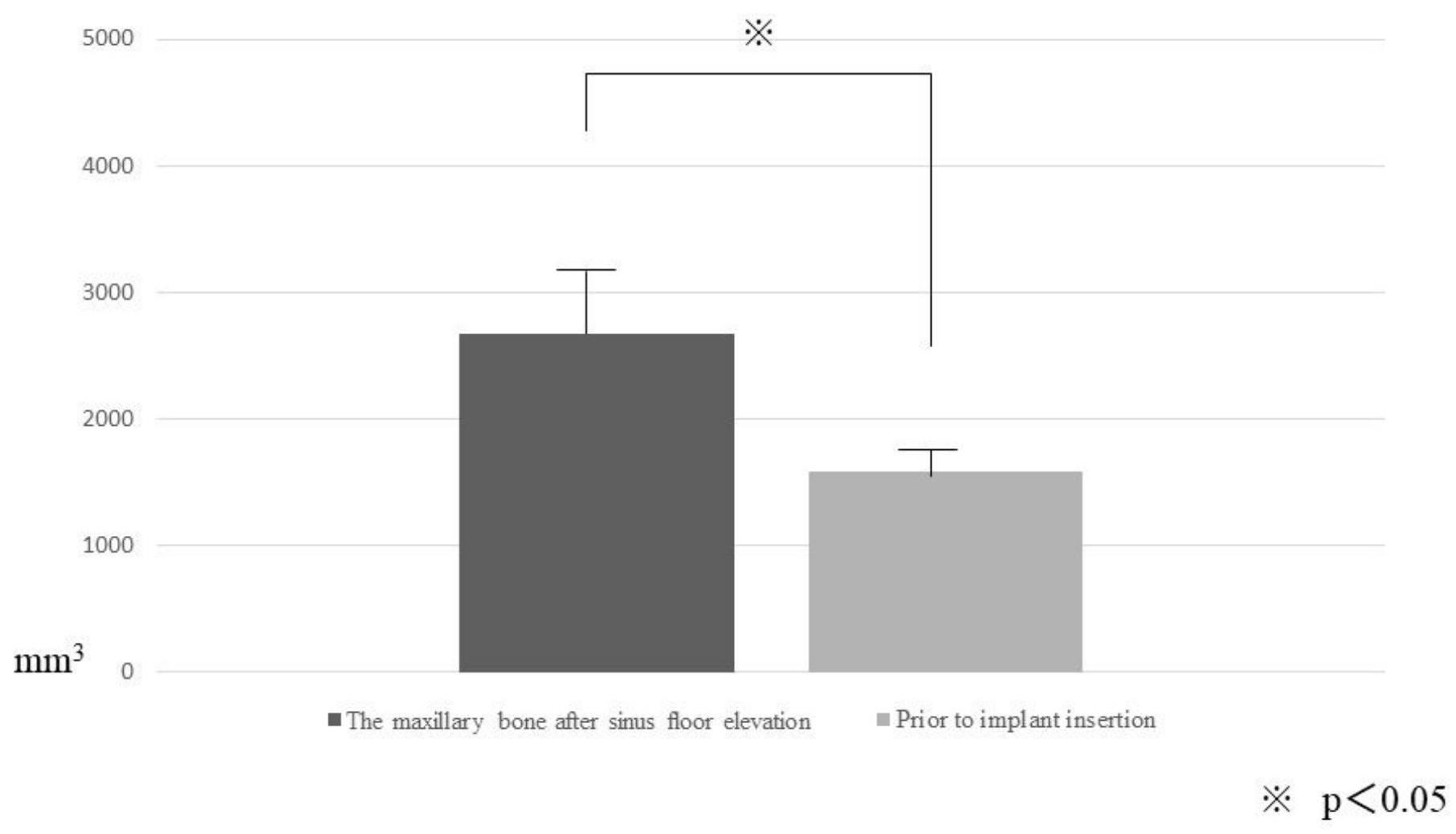

Figure 8

The average volumes of the maxillary bone after sinus floor elevation and prior to implant insertion. The average volume prior to implant insertion is significantly lower than after sinus floor elevation. 


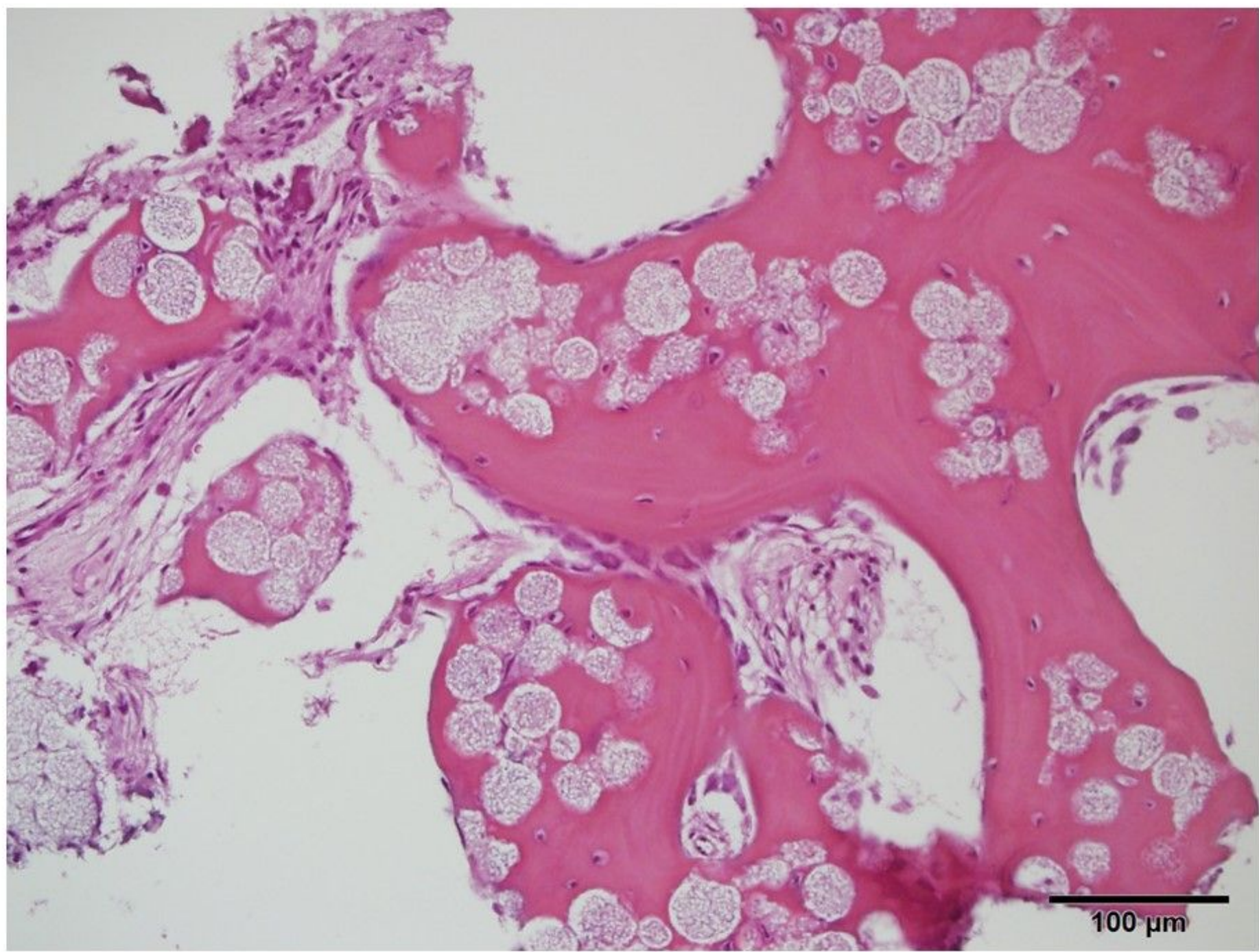

\section{Figure 9}

Histologic view of biopsy material in the newly formed bone area, hematoxylin and eosin staining (H\&E). 


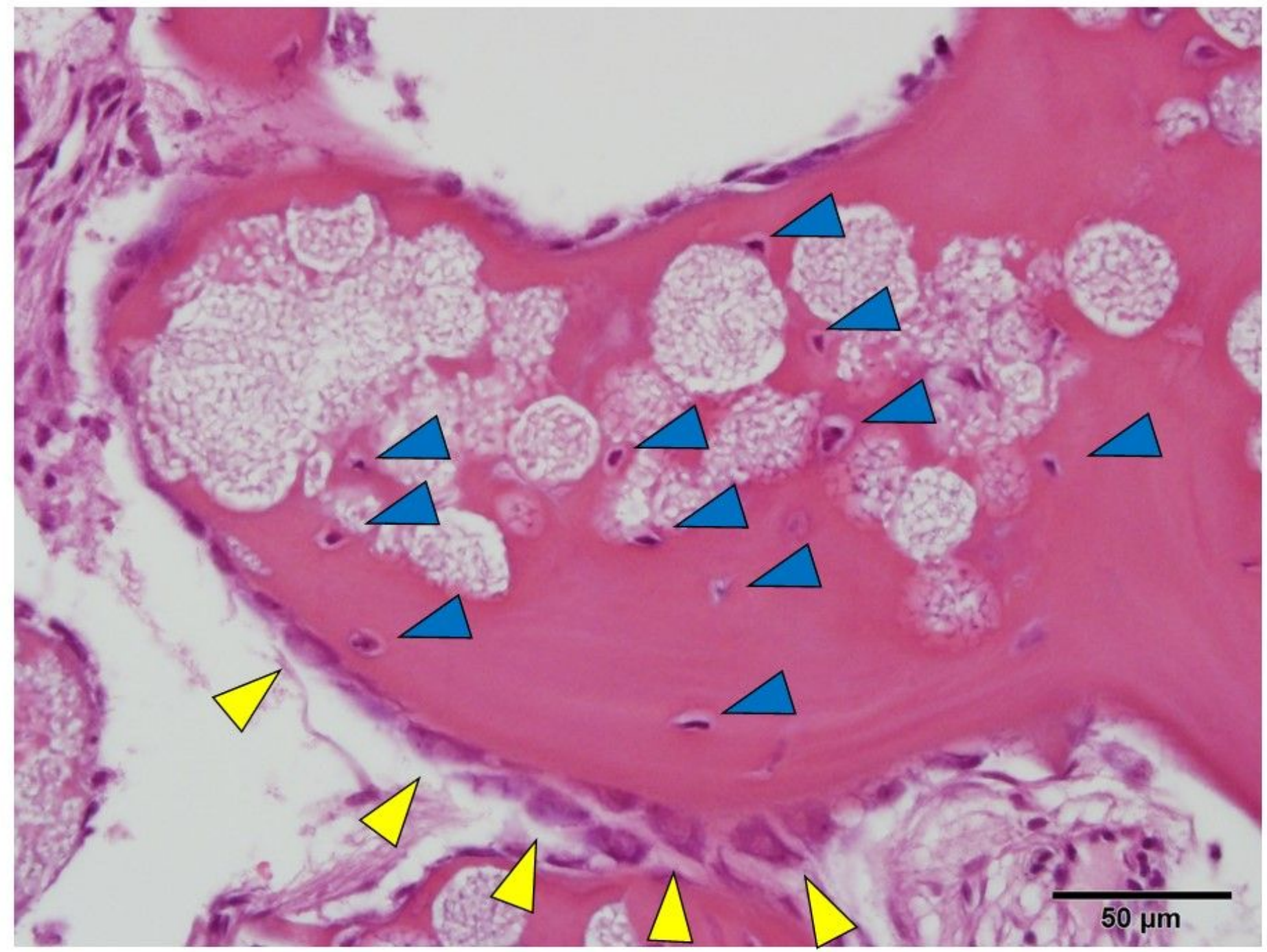

Figure 10

Detail of Fig. 7 (magnification Fig. $7 \times 2$ ). Yellow arrows: Osteoblasts Blue arrows: Osteocytes 